\title{
Políticas Educacionais do Brasil e Estados Unidos para o Atendimento de Alunos com Altas Habilidades/Superdotaçáo (AH/SD) ${ }^{\mathbf{1}}$ Brazilian and American Educational Policies to Assist Gifted Students
}

\author{
Brenda Cavalcante MATOS ${ }^{2}$ \\ Carina Elisabeth MACIEL ${ }^{3}$
}

\begin{abstract}
RESUMO: o texto tem por objetivo analisar as políticas educacionais para o atendimento dos alunos com Altas Habilidades/ Superdotação (AH/SD) no Brasil e nos Estados Unidos. Define o conceito de Altas Habilidades/Superdotaçáo e apresenta o papel da Educação Especial nesse contexto. Informa sobre conceitos preestabelecidos e mitos enraizados na sociedade envolvendo esses alunos e a necessidade que eles têm de um atendimento especializado para atender suas necessidades educacionais especiais. Informa sobre os tipos de atendimento que atualmente estão disponíveis para a educação desses alunos. Trata-se de um ensaio que se baseia em análise documental e discussão de dados obtidos por meio de literatura específica sobre o tema Altas Habilidades/ Superdotação. A discussão fornece elementos para afirmar que as políticas americanas não determinam como as açốes devem ser implantadas, mas apenas indicam a necessidade de realização das mesmas. Já no Brasil, as políticas não só determinam quais as açôes devam ser feitas, mas também indicam como elas devem ser realizadas. O atendimento especializado, preconizado pelas legislaçóes, favorece o ensino de alunos com AH/SD com base em atividades específicas, diferenciadas e direcionadas para sua área de domínio. Possibilita a ampliaçáo dos conhecimentos desses alunos oferecendo condiçóes para o desenvolvimento de seus estudos de forma mais efetiva, atendendo as necessidades educacionais especiais apresentadas.
\end{abstract}

PALAVRAS-CHAVE: Educação Especial. Políticas Educacionais. Altas Habilidades/Superdotação.

ABSTRACT: This paper has the objective to analyze educational policies in Brazil and in the United States to assist gifted students. It also defines the concept of giftedness and presents the role of Special Education in this context. It reports on pre-established concepts and rooted myths in society involving these students and their need for a specialized service to meet their special educational needs. It also reports on the types of services that are currently available for these students' education. This essay is based on document analysis and discussion of data obtained from specific literature about gifted students. The results indicate that American policies do not determine how actions should be implemented, but only indicate the need for meeting them. While in Brazil, policies not only determine which actions should be taken, but also indicate how they should be carried out. Specialized service, advocated by the legislation, favors the teaching of gifted students based on specific activities differentiated and targeted to their domain area. It enables the expansion of these students' knowledge providing conditions for a more effective development of their studies assisting their special educational needs.

KEYWORDS: Special Education. Educational Policies. Gifted/Talented.

\section{INTRODUÇÁ̃}

O quadro de Altas Habilidades/Superdotação (AH/SD) tem sido um tema pouco conhecido e discutido entre os professores e membros atuantes da área de educação em geral (PÉREZ; FREITAS, 2009). Devido a dificuldade do reconhecimento desse quadro de Educação Especial, não são feitas as intervençôes diferenciadas necessárias para proporcionar uma aprendizagem efetiva a esses alunos.

\footnotetext{
${ }^{1}$ http://dx.doi.org/10.1590/S1413-65382216000200003

${ }^{2}$ Graduada em Ciências Biológicas, Licenciatura, pela Universidade Federal de Mato Grosso do Sul - UFMS. Campo Grande, MS, Brasil.brendacmatos@gmail.com

${ }^{3}$ Doutora em educaçấo pela UFMS. Docente do PPGEDu/UFMS. Campo Grande, MS, Brasil. carina22em@yahoo.com.br
} 
Este artigo busca investigar como estão sendo articuladas as propostas político-pedagógicas para um ensino que desenvolva melhor ação nesse campo da Educação Especial, utilizando como fonte, experiências político-educacionais realizadas nos Estados Unidos e no Brasil. Dessa forma, por meio de pesquisas em fontes bibliográficas e documentais, esse ensaio tem como objetivo analisar políticas educacionais para o atendimento dos alunos com Altas Habilidades/Superdotação no Brasil e nos Estados Unidos. No estudo, define-se o conceito de Altas Habilidades/Superdotação e apresenta o papel da Educação Especial nesse contexto, informa sobre conceitos preestabelecidos e mitos enraizados na sociedade envolvendo esses alunos e a necessidade que eles têm de atendimento especializado para suas necessidades educacionais especiais, bem como os tipos de atendimento que atualmente estão disponíveis para a educação desses alunos.

O ensaio se baseia em análise documental e discussão de dados obtidos por meio de literatura específica sobre o tema Altas Habilidades/Superdotação. Esses dados foram levantados por meio de pesquisa bibliográfica em livros, publicaçóes de trabalhos e artigos científicos na área de Educação e Educação Especial; trabalhos apresentados nas Reunióes da Associação Nacional de Pós-Graduação e Pesquisa em Educação (ANPEd) no grupo de trabalho 15 (GT15), que tratam sobre temas na área de Educação Especial e representam a publicação de pesquisas desenvolvidas na área específica; além da busca de informaçóes em documentos oficiais do Ministério da Educação (MEC); manuais da Secretaria de Educação Especial (SEESP); legislações brasileiras e americanas dentre outros.

\section{EducaÇão Especial - um direito dos alunos com Altas Habilidades/SuperdotaÇáo}

Está fundamentado na Constituição Brasileira de 1988, no artigo 205, que a Educação é direito de todos os brasileiros (BRASIL, 1988). Entretanto, foi reconhecido a partir da elaboração da Política Nacional de Educação Especial de 1994, que existem pessoas na população brasileira que possuem necessidades especiais concernentes à sua Educação. Passa a ser regulamentada com a implementação da Política Nacional de Educação Especial (BRASIL, 1994), a definição do termo "Pessoa Portadora de Necessidades Especiais" como aquela:

[...] que apresenta, em caráter permanente ou temporário, algum tipo de deficiência física, sensorial, cognitiva, múltipla, condutas típicas ou altas habilidades, necessitando, por isso, de recursos especializados para desenvolver mais amplamente o seu potencial e/ou superar ou minimizar suas dificuldades. No contexto escolar, costumam ser chamadas de pessoas portadoras de necessidades educativas especiais. (BRASIL, 1994, p. 22, grifo nosso).

No documento mencionado, a pessoa com Altas Habilidades/Superdotação (AH/ SD) é identificada como "Pessoa Portadora de Necessidades Especiais", ou seja, público-alvo da Educação Especial, antes mesmo da publicação da Lei de Diretrizes e Bases da Educação Nacional - LDB/1996. Assim, esse grupo passa a ser beneficiado pelo atendimento especializado promovido pela Educaçáo Especial como um direito constitucional brasileiro (BRASIL, 1996). Com a lei de ${ }^{\circ} 10.172$, de janeiro de 2001 que estabelece o Plano Nacional de Educação (BRASIL, 2001), fica definido que: 
A educação especial se destina às pessoas com necessidades especiais no campo da aprendizagem, originadas quer de deficiência física, sensorial, mental ou múltipla, quer de características como altas habilidades, superdotação ou talentos (BRASIL, 2001, s.p., grifo do autor).

A alteração do termo de "Pessoa Portadora de Necessidades Especiais" para o termo "Pessoa com Necessidades Especiais" passa a preponderar na legislação nacional (GARCIA; MICHELS, 2011), mas continua tendo como parte de seu público-alvo pessoas com Altas Habilidades/Superdotação, que consistem no foco principal deste trabalho.

\subsection{Altas Habilidades/Superdotaçáo - Definiçấo do CONCeito}

Para determinar o tipo de atendimento especializado preconizado para os alunos com esse quadro, é necessário entender primeiramente o que significa Altas Habilidades/ Superdotação. De acordo com a Política Nacional de Educação Especial na Perspectiva da Educação Inclusiva (BRASIL, 2008):

Alunos com altas habilidades/superdotação demonstram potencial elevado em qualquer uma das seguintes áreas, isoladas ou combinadas: intelectual, acadêmica, liderança, psicomotricidade e artes. Também apresentam elevada criatividade, grande envolvimento na aprendizagem e realizaçáo de tarefas em áreas de seu interesse (BRASIL, 2008, p.15).

Da mesma forma, segundo definiçóes do documento "Altas Habilidades/Superdotação: Encorajando Potenciais" (BRASIL, 2007), da Secretaria de Educação Especial (SEESP):

[...] os termos "pessoas com altas habilidades" e "superdotaçáo" são mais apropriados para designar aquela criança ou adolescente que demonstra sinais ou indicaçóes de habilidade superior em alguma área do conhecimento, quando comparada aos seus pares (BRASIL, 2007, p.7).

A definição de alunos com AH/SD trazida por esses dois documentos oficiais da federação, que tratam de Educação Especial, esclarecem que as pessoas com Altas Habilidades/ Superdotação podem demonstrar tal condição em diversas áreas do conhecimento em unicidade ou de forma concomitante, e demonstram um desempenho acima da média, em suas áreas de interesse, quando comparados aos demais alunos de mesma faixa etária e nível de escolaridade. Devido a essas características marcantes dos alunos com AH/SD, faz-se necessário políticas públicas que regulamentem um atendimento especializado e direcionado a esses alunos.

A Educação Especial é responsável por organizar e oferecer, junto com a escola, esse atendimento educacional especializado a alunos com AH/SD. Esse atendimento não visa de forma alguma substituir o ensino regular, ele na verdade atua de forma conjunta, articulada e suplementar ao ensino comum, e era da SEESP a responsabilidade de orientar o atendimento das necessidades educacionais especiais desses alunos (BRASIL, 2008, 2010, 2011). Nos últimos anos a Secretaria de Educação Especial (SEESP) foi substituída pela Secretaria de Educação Continuada, Alfabetização, Diversidade e Inclusão (SECADI), que passou a ser dividida em diretorias visando a efetivação de políticas públicas para a regulamentação dos atendimentos especializados para cada categoria de estudantes atendimentos por essa Secretaria, que definitivamente inclui a categoria de Educação Especial (BRASIL, 2012). 


\subsection{Políticas Educacionais para pessoas com Altas Habilidades/Superdotação no BRASIL}

Remontam à época de 1960, no Brasil, as primeiras prescriçóes normativas sobre a formação de professores para atuarem com pessoas com necessidades educacionais especiais. A Campanha Nacional de Educação e Reabilitação de Deficientes Mentais (CADAME) colaborou com o então Ministro da Educação e Cultura, Pedro Paulo Penido, para a aprovação do Decreto no 48.961, de 22 de setembro de 1960 (MAZZOTTA, 2003; JANUZZI, 1992), documento que aponta, no artigo $3^{\circ}$, a forma como devia ser desenvolvida "[...] a educação, treinamento, reabilitação e assistência educacional das crianças retardadas e outros deficientes mentais de qualquer idade ou sexo". Porém, não houve menção à educação especial de superdotados.

A política para a Educação Especial no Brasil é apresentada por vários autores importantes da área (MAZZOTTA, 2003; JANUZZI, 1992; BUENO, 1993), entretanto, nesse trabalho objetivamos identificar as políticas específicas para pessoas com Altas Habilidades/ Superdotação. Assim, o recorte das políticas apresentadas tem como baliza documentos que preconizam o atendimento a esse público-alvo: AH/SD.

A primeira menção de Educação para “alunos excepcionais”, nas políticas públicas brasileiras, aconteceu na Lei de Diretrizes e Bases da Educação Nacional (LDB) aprovada em 1961 (BRASIL, 1961). Porém, somente 10 anos depois, em 1971,

com a promulgação da Lei de № 5.692/71, a LDB incluiu explicitamente as diretrizes para o ensino de "superdotados" no Artigo $9^{\circ}$ da que afirma que "os superdotados deverão receber tratamento especial, de acordo com as normas fixadas pelos competentes Conselhos de Educação" (BRASIL, 1971, s.p.).

Em seguida, no ano de 1973, foi criado o Centro Nacional de Educação Especial (CENESP), que agia vinculado ao MEC com o intuito de promover açóes educacionais e financiar açóes de atendimento ao portador de necessidades especiais, que inclui tanto as deficiências quanto as AH/SD (BRASIL, 2008). Com base na Portaria Ministerial no 550, o CENESP definiu seu Regimento Interno, o qual dispóe nos caput e parágrafo único do art. $2^{\circ}$ :

O CENESP tem por finalidade planejar, coordenar e promover o desenvolvimento da Educaçáo Especial no período pré-escolar, nos ensinos de $1^{\circ}$ e $2^{\circ}$ graus, superior e supletivo, para os deficientes da visão, da audiçấo, mentais, físicos portadores de deficiência múltiplas, educandos com problemas de conduta e os superdotados, visando à sua participaçáo progressiva na comunidade, obedecendo aos princípios doutrinários, políticos e científicos que orientam a Educação Especial (MAZZOTTA, 2003, p.57, grifo nosso).

A criação desse órgão representa uma inclusão legal do quadro da Educação Especial na lista de responsabilidades e preocupaçóes do governo. Após 13 anos, em 1986, esse órgão - CENESP - foi substituído pela Secretaria de Educação Especial (SEESP) que prontamente publicou manuais para a orientação do ensino de alunos com AH/SD. Finalmente, por meio da elaboração do Plano Nacional de Educação (Lei Federal No 10.172 de janeiro de 2001) e das Diretrizes Nacionais da Educação Especial na Educação Básica, em setembro de 2001, foi determinado a implantação de programas de atendimento especializado aos alunos 
com Altas Habilidades/Superdotação nas áreas artísticas, intelectual e psicomotora (BRASIL, 2001). Entretanto, no ano de 2004, Prieto realizou um trabalho chamado "Políticas de inclusão escolar no Brasil”, e, ao analisar cinco municípios brasileiros, dentre eles Campo Grande/ MS, ele retratou as dificuldades de identificação do quadro de altas habilidades, assim como a carência de serviços adequados a esses alunos ou até mesmo a falta total de atendimento a esses alunos em alguns destes municípios (PRIETO, 2004). Somente, no ano de 2005, em parceria com a Organização das Naçóes Unidas para Educação, Ciência e Cultura (UNESCO), com o Fundo Nacional de Desenvolvimento da Educação (FNDE) e as Secretarias de Educação, são criados os Núcleos de Atividades de Altas Habilidades/Superdotação (NAAH/S) em todos os 27 territórios brasileiros, que passaram a ser referência de atendimento aos alunos com AH/ $\mathrm{SD}$, disponibilizando recursos didáticos e pedagógicos para o ensino dos mesmos e realizando a formação de professores que atuam com esses alunos, para que fossem capazes de atender os desafios vinculados à condição que esses alunos apresentam (BRASIL, 2007, 2008; PÉREZ; FREITAS, 2009). Estes núcleos são preconizados na política educacional e representam uma resposta às necessidades da sociedade, e esses alunos, que por muito tempo foram tidos como 'inexistentes', passam a ganhar direitos e tratamento apropriado às suas necessidades especiais.

O Censo do Instituto Nacional de Estudos e Pesquisas (BRASIL, 2007) indica 2.982 alunos com Altas Habilidades/Superdotação no Brasil. Já a Organização Mundial da Saúde (OMS), estima a porcentagem de 3,5 a 5\%, aproximadamente oito milhóes de pessoas, que apresentam AH/SD no nosso país (PÉREZ, 2007). Entretanto, para esse índice foram consideradas apenas altas habilidades nas áreas linguística e lógico-matemática, consideradas áreas cognitivas baseadas em testes de Quociente de Inteligência (QI). Pesquisas que levam em consideraçáo outros tipos de inteligência além da cognitiva indicam que esse número pode chegar até 7,78\% da população brasileira (PÉREZ, 2007; PÉREZ; FREITAS, 2009). Esses dados indicam um elevado percentual de alunos com AH/SD e que necessitam de atendimento específico. No Brasil os Núcleos de Atividades de Altas Habilidades/Superdotação (NAAH/S) representam uma conquista materializada em 2005.

\subsection{Políticas Educacionais para pessoas com Altas Habilidades/Superdotaçáo nos Estados Unidos}

Historicamente, o movimento para o ensino dos alunos com AH/SD nos Estados Unidos começou em meados de 1900, após o estabelecimento de testes pioneiros para a identificação desses alunos (ANDRÉS, 2010; VIRGOLIM, 2014). Em seguida, começaram a surgir e se estabelecer em 1920, escolas e classes especiais para o atendimento desses alunos em todo país. A partir daí, os programas para AH/SD começaram a se popularizar até serem interrompidos temporariamente devido à Grande Crise financeira de 29 e a Segunda Guerra Mundial. Com a volta das atividades em torno de 1950, grandes organizaçóes passaram a se unir a fim de "garantir o sucesso do objetivo de colocar os jovens mais brilhantes dos Estados Unidos entre os melhores concorrentes internacionais dos certames de matemática e ciências" (ANDRÉS, 2010, p.33). Seguindo essa tendência, pesquisas apontam que a atenção dos norte americanos às Altas Habilidades/Superdotação cresceu muito a partir de 1960 (ANDRÉS, 2010). Apesar de tudo isso, não existe uma lei federal nos Estados Unidos que exija dos estados ou municípios 
Educação Especial para alunos com Altas Habilidades/Superdotação (TURNBULL, 2013). A maioria das decisóes sobre o tipo de educação oferecida para os alunos com AH/SD, é feita pelos municípios e estados de forma independente.

As políticas locais e a disponibilidade de recursos variam muito de estado para estado dentro do país, o que provoca uma diferença significativa na oferta de serviços para o atendimento de alunos com AH/SD entre os estados americanos (ANDRÉS, 2010). Por isso, o Gifted and Talented Students Education Act (Lei para a Educação de Estudantes Superdotados e Talentosos) de 1998, previa uma canalização de recursos para os estados americanos, que visava fortalecer programas e serviços oferecidos para alunos superdotados, e reforçava com mais investimentos financeiros as iniciativas já realizadas (ANDRÉS, 2010). Porém, a diferença entre estados ainda é grande, como mostra uma pesquisa americana conduzida pela National Association for Gifted Children - NAGC (Associação Nacional para Crianças Superdotadas) em 2009, que demonstra que 32 dos 50 estados americanos, possuem políticas educacionais que exigem a identificação dos alunos, a provisão do serviço, ou ambos. E dentre estes estados, cinco não oferecem nenhum tipo de recurso financeiro para esse fim enquanto seis deles têm esses serviços 100\% financiados pelo governo (TURNBULL, 2013). Os financiamentos são dirigidos às escolas públicas ou a instituiçóes privadas que oferecem os serviços de atendimento a esse público. Porém, mesmo com financiamento, as instituições privadas ainda assim, cobram pelo serviço de atendimento a esses alunos.

O tipo de serviço oferecido aos alunos com AH/SD é decidido localmente, por políticas municipais e/ou estaduais. Os serviços oferecidos são variados e podem incluir programas de aceleração de séries, agrupamentos de estudantes, aceleração ou compactação de currículo, diferenciaçáo do ensino com aulas avançadas e enriquecimento curricular, por meio de registro duplo em classes ou séries diferentes, ou até mesmo em escolas ou programas especializados para esses alunos. Para isso, o aluno pode ser acomodado em classes regulares na escola comum, ao mesmo tempo em que também está matriculado em classes especiais ou pode formar grupos em tempo integral com estudantes que apresentem habilidades similares (ANDRÉS, 2010).

Os serviços de aceleração de séries, agrupamentos de estudantes e aceleração e compactação de currículo, são oferecidos pelas escolas comuns que atendem esses alunos, sem custo adicional. Enquanto os serviços de diferenciação do ensino com aulas avançadas e o enriquecimento curricular, são oferecidos por instituições privadas com custo adicional às famílias.

Pérez (2007) relata que quase todos os estados americanos possuem programa de seleção de alunos com AH/SD por meio de testes de identificação. Ela também acrescenta que, quando reconhecida a alta habilidade do aluno, este é retirado da sala de aula regular, durante as atividades relacionadas à área de conhecimento que ele apresenta capacidade acima da média, e é levado para participar de uma turma mais adiantada na qual recebe atendimento especializado para aquele assunto específico que ele domina. Seu relato endossa a descrição de Andrés (2010) sobre o registro duplo em classes ou séries diferentes.

Além desses serviços oferecidos nas escolas regulares, cerca de 15 estados americanos possuem escolas secundárias para alunos que apresentam altas habilidades em matemática e ciências ou em artes e ciências humanas. A maioria desses programas é realizada em campi universitários durante as férias escolares. Esses programas de férias apresentam diferentes requisitos 
para ingresso como apresentação de histórico escolar e/ou resultado de teste de altas habilidades/superdotação. O horário geralmente é integral e é oferecido residência para esses alunos no próprio campus universitário (ANDRÉS, 2010).

Segundo Stephens e Karnes (2000 apud TURNBULL, 2013, p.372), a maioria dos estados americanos adota a definição de superdotação oferecida pela lei federal de 1978, que diz que:

[...] o termo 'crianças com altas habilidades e superdotação' se refere a crianças - e quando aplicável, jovens - que sáo identificados na pré-escola, fundamental, ou ensino médio, como possuidores de habilidades demonstradas ou habilidades potenciais que dâo evidências de alta capacidade de performance em certas áreas como intelectual, criativa, especificamente acadêmica, ou habilidades de liderança, ou na execução de artes visuais, e que em virtude disso, requer serviços ou atividades que não são normalmente providas pela escola. (UNITED STATES OF AMERICA, 1978, p.150, traduçáo nossa).

Numa definição mais recente do conceito, o U.S Department of Education (Departamento Norte Americano de Educação) (1993 apud NATIONAL SOCIETY FOR THE GIFTED AND TALENTED, 2014), definiu os estudantes superdotados como:

Crianças e jovens com talento excepcional que atingem ou mostram o potencial para atingir altos e notáveis níveis de realizaçóes quando comparados com outros da sua idade, experiência ou ambiente. (apud NATIONAL SOCIETY FOR THE GIFTED AND TALENTED, 2014, s.p., tradução nossa).

Segundo o National Center for Education Statistics (Centro Nacional de Estatísticas em Educação) (TURNBULL, 2013), em 2010 havia nos Estados Unidos aproximadamente 3,2 milhóes de estudantes, da pré-escola ao $3^{\circ}$ ano do ensino médio, que eram academicamente superdotados. Como critério de classificação, eles identificam estudantes superdotados pela demonstração de 125 a 130 de QI, segundo esse critério, de 2 a 3\% da população geral é classificada como superdotada (TURNBULL, 2013). Entretanto, os testes de QI e outros testes psicométricos estão restritos à medição de altas habilidades relativas aos aspectos intelectuais e acadêmicos, excluindo os aspectos de liderança, psicomotricidade e artes (VIRGOLIM, 2014). Estima-se que, se outros testes forem levados em consideração, esse número percentual de prevalência de AH/SD na população pode ser consideravelmente maior (PÉREZ, 2007).

\subsection{CoMparativo histórico SObre AS AÇÓES PARA AS ALTAS HABILIDADES/SUPERDOTAÇÃO no Brasil e Estados Unidos}

As açôes mais significativas em prol da Educação de indivíduos com AH/SD no Brasil e Estados Unidos já foram descritas anteriormente, porém, a tabela a seguir tem o objetivo de resumir e expor de forma mais visível a linha do tempo dessas ações. 


\begin{tabular}{|c|c|c|}
\hline ANO & PAÍS & AÇÁO \\
\hline 1900 & EUA & Surgem os testes pioneiros para identificação de $\mathrm{AH} / \mathrm{SD}$ \\
\hline 1920 & EUA & Criam-se escolas e classes especiais para superdotados em todo país \\
\hline 1950 & EUA & Grandes organizaçóes se unem para investir na educação de superdotados \\
\hline 1960 & EUA & Pesquisas apontam que interesse de norte-americanos cresce em relação às $\mathrm{AH} / \mathrm{SD}$ \\
\hline 1961 & Brasil & $\begin{array}{l}\text { Primeira menção à educaçáo de alunos excepcionais na Lei de Diretrizes e Bases da } \\
\text { Educaçấo (LDB) }\end{array}$ \\
\hline 1971 & Brasil & LDB inclui explicitamente diretrizes para ensino de superdotados \\
\hline 1973 & Brasil & Surge o Centro Nacional de Educação Especial (CENESP) \\
\hline 1978 & Brasil & Fundada a Associação Brasileira de Superdotados em seis estados brasileiros \\
\hline 1978 & EUA & Lei federal define o termo AH/SD \\
\hline 1986 & Brasil & CENESP é substituído pela Secretaria de Educação Especial (SEESP) \\
\hline 1993 & EUA & Atualização da definição do termo AH/SD a nível federal \\
\hline 1998 & EUA & Lei prevê canalizaçáo de recursos para atendimento de AH/SD \\
\hline 2003 & Brasil & É fundado o Conselho Brasileiro para Superdotação (ConBraSD) em todos os estados \\
\hline 2005 & Brasil & $\begin{array}{l}\text { A SEESP cria os Núcleos de Atividades de Altas Habilidades/Superdotaçáo (NAAH/S) } \\
\text { nos } 27 \text { territórios brasileiros. }\end{array}$ \\
\hline
\end{tabular}

Quadro 1 - Comparação de açóes políticas e sociais para a educação de alunos com Altas Habilidades/Superdotação (AH/SD)

Fonte: Elaboração própria.

É importante notar que as ações pela Educação para AH/SD começaram historicamente mais cedo nos Estados Unidos. Mais de 60 anos antes de ser feita a primeira mençáo à Educação de alunos especiais no Brasil, os Estados Unidos já desenvolviam testes para a identificação de alunos com AH/SD. Apesar do termo "alunos excepcionais" já ser referido na Lei de Diretrizes e Bases da Educação Nacional em 1961, os alunos com AH/SD ainda não haviam sido explicitamente inclusos na lei e somente em 1971 eles foram contemplados por meio de menção direta. Enquanto isso, no mesmo período nos Estados Unidos, alunos com AH/SD já desfrutavam de escolas e classes especiais, bem como do investimento de grandes organizaçóes na educação desses indivíduos.

A Associação Brasileira de Superdotados, fundada no Brasil em 1978, e o Conselho Brasileiro para Superdotação (ConBraSD) criado em 2003, são marcos de açóes e iniciativas da sociedade em prol da Educação de Superdotados. Apesar de serem iniciativas sociais, eles surgem apenas após determinaçóes importantes do governo que definiam e regulamentavam açóes para a Educação de AH/SD, como a elaboração dos artigos de lei referentes às AH/SD na LDB e a criação do Centro Nacional de Educação Especial (CENESP) em 1973 e sua substituição pela Secretaria de Educação Especial (SEESP) em 1986. Portanto, podemos dizer que no Brasil as açôes sociais surgem como consequência às ações políticas. $\mathrm{O}$ mesmo não se vê no cenário 
americano, em que primeiro observamos a ação da sociedade com o investimento das grandes organizações, criações de classes e escolas especiais, o crescente interesse da população e somente em 1978, uma lei federal define o termo e 20 anos depois - 1998 - prevê a canalização de recursos para o investimento na educação desses alunos. Percebemos que nos Estados Unidos as ações governamentais surgem como consequência da ação da sociedade na educação desses alunos, quadro que ainda se mantêm no país até hoje. Em resumo, enquanto no Brasil as açóes partem principalmente do governo para a sociedade, nos Estados Unidos essas açóes partem principalmente da sociedade gerando como consequência, açóes governamentais.

\subsection{Importância de Programas específicos para alunos com AH/SD}

Por serem considerados acima da média, muitos acreditam que os alunos com AH/ SD não precisam de atendimento especializado. Somado a isso, ainda há a crença de que alunos com deficiência físicas e intelectuais são mais carentes desses serviços do que os alunos com altas habilidades. Essa idéia está arraigada a um preconceito inconsciente de que as deficiências precisam de auxílio, enquanto que os superdotados já são privilegiados (PÉREZ; FREITAS, 2009). Pérez (2007) dá a sua opiniẫo de que:

A própria legislação valoriza mais a inclusão de alunos com deficiência, e pouca gente reconhece que, como estes, o aluno com altas habilidades também precisa de educação especial. A idéia de que deficientes têm maior necessidade de atendimento especial é falsa. O que acontece é que a pessoa com deficiência, por possuir algo a menos, provoca na sociedade um sentimento de culpa. O superdotado, ao contrário, causa um misto de ódio e inveja, quando identificado, ou indiferença. [...] A necessidade do deficiente é, de fato, mais evidente. É preciso dar reforço para o deficiente mental, adaptar a sala de aula para o cadeirante, criar material em braile para o cego... No caso das altas habilidades, não é necessário um recurso externo físico para que o estudante seja atendido. O que ele precisa é de uma adaptação curricular, de uma estratégia pedagógica diferenciada (PÉREZ, 2007, p.10).

Alunos com AH/SD são alunos com Necessidades Educacionais Especiais, eles enfrentam obstáculos nos estudos e necessitam de adaptação de currículo e/ou estratégias pedagógicas diferenciadas, e por isso são atendidos pela Educação Especial (BRASIL, 2008). Devido à capacidade de assimilação acima da média dos colegas, o aluno com AH/SD apresenta muitas vezes dificuldade de concentração durante as aulas, e outras vezes se sente entediado e desmotivado (PÉREZ, 2007). Sem interesse, esse aluno deixa de participar das aulas, algumas vezes até atrapalhando o andamento da classe com atividades paralelas que para ele parecem bem mais interessantes.

De maneira geral, o professor tem dificuldade de reconhecer esse desinteresse (PÉREZ, 2007), ou quando reconhece, diagnostica essa atitude como mau comportamento e não como a falta de uma atividade que estimule o aluno em sua capacidade intelectual superior. Muitos questionam a necessidade de programa especiais para alunos com Altas Habilidades/ Superdotação. No entanto, para Tolan (1990), crianças superdotadas tem duas necessidades primárias, a primeira é que precisam se sentir confortáveis com elas mesmas e com a diferença que simultaneamente abre possibilidades e cria dificuldades; e segundo, elas precisam desenvol- 
ver seu potencial. As dificuldades citadas por Pérez (2007) e Tolan (1990) não estão relacionadas as habilidades acadêmicas, mas a maior parte do tempo, estão relacionadas com habilidades sociais, cuja relação é dialética, ou seja, uma condição interfere na outra.

A reunião de estudantes com altas habilidades em programas especializados cria um ambiente onde podem se sentir confortáveis estudando junto com pares que apresentam necessidades educacionais semelhantes, possibilitando assim o desenvolvimento de suas potencialidades. Para isso, metodologias de ensino e práticas pedagógicas diferenciadas são desenvolvidas para apresentar assuntos complexos e uma ampla gama de informaçóes em um curto período de tempo. Tolan (1990) endossa essa prática quando explica que crianças superdotadas não somente aprendem mais rápido que outras, mas também aprendem de maneira diferente. Também diz que métodos de ensino tradicional tomam assuntos complexos e os quebram em assuntos menores, como pequenas doses que são apresentadas uma de cada vez, porém as mentes superdotadas podem consumir grandes quantidades de informação de uma só vez, aumentando gradativamente em complexidade. E ainda acrescenta dizendo que dar a essas crianças apenas pequenas porções de informação é como alimentar um elefante com uma folha de grama de cada vez, de forma que ele vai morrer de fome antes mesmo que perceba que alguém está tentando alimentá-lo. Em concordância com Tolan (1990), Turnbull (2013) afirma que os alunos superdotados são beneficiados por professores que ensinam de maneiras não-convencionais e que desafiam os alunos a atingirem seu completo potencial.

Para suprir essas necessidades apresentadas por alunos com AH/SD, faz-se necessário desenvolver programas de atendimento especializado que sejam adequados às suas necessidades educacionais especiais desses alunos. A Política Nacional de Educação Especial na Perspectiva da Educação Inclusiva afirma claramente que os alunos com AH/SD são alvo de atendimento educacional especializado em todas as etapas e modalidades da Educação (BRASIL, 2008). No Decreto 7611/11 estão determinados tanto os tipos de atendimento especializado oferecido aos alunos com AH/SD quanto a responsabilidade técnica e financeira do MEC na ampliação desses serviços (BRASIL, 2011). De acordo com este documento (BRASIL, 2011) e também com a Nota Técnica n 04 (BRASIL, 2014), emitida pela Diretoria de Políticas de Educação Especial da SECADI, no Artigo $2^{\circ}$, parágrafo $1^{\circ}$ e inciso II; os serviços oferecidos pelo atendimento educacional especializado - compreendido como o conjunto de atividades, recursos pedagógicos organizados institucionalmente e continuamente - devem ser prestados de forma "suplementar à formação de estudantes com altas habilidades/superdotação" (BRASIL, 2014, p.3). De maneira nenhuma os serviços de atendimento especializado visam substituir a educação regular. Na página da Secretaria de Educação Especial do Ministério da Educação, pode ser encontrada a seguinte afirmaçáo:

No Brasil não existe escola especial para pessoas com altas habilidades/superdotadas. O sistema regular de ensino em classe comum deverá assegurar a matrícula de todo e qualquer aluno, conforme a legislaçáo, organizando-se para o atendimento aos educandos com necessidades educacionais especiais. $\mathrm{O}$ aluno com Altas Habilidades/Superdotado deverá receber atendimento suplementar em Salas de Recursos ou em outros espaços definidos pelo sistema em horário contrário ao das aulas regulares (MAIA, 2004, p.6, grifo do autor). 
Entretanto, muitas vezes esse direito ao atendimento especializado, em salas e horários diferenciados, não é assegurado. Segundo Andrés (2010), em muitos casos, estes alunos precisam contar com um pai persistente, um professor interessado ou um administrador de escola inovador para que se sintam suficientemente motivados em sala de aula. Essa nem sempre é uma tarefa fácil, e por isso, é necessário aumentar a conscientização sobre a importância da qualidade do programa de ensino para alunos dotados de altas capacidades.

Os tipos de atendimentos especializados oferecidos aos alunos com AH/SD podem variar de acordo com as políticas públicas vigentes ou das decisóes dos governos municipais e estaduais tanto no Brasil quanto nos Estados Unidos, porém, todos esses atendimentos podem ser separados de modo geral em duas categorias básicas: aceleração e compactação de currículo; ou enriquecimento curricular. De acordo com Pérez (2007):

$\mathrm{O}$ método do enriquecimento, bastante aplicado no Brasil, é mais adequado. $\mathrm{O}$ aluno com altas habilidades freqüenta sua turma regularmente e no contra-horário recebe atendimento individual de um professor especializado, que irá trabalhar com projetos específicos (PÉREZ, 2007, p.9).

\section{Endossando Pérez (2007), Ribeiro e Souza (2014) relatam que:}

[...] o NAAH/S - Núcleo de Atividades em Altas Habilidades/Superdotação - desenvolve esse trabalho nas salas de enriquecimento curricular que estimula os alunos a se aprofundarem em seus domínios, a planejarem e organizarem suas tarefas, a participarem de grupos de estudo e pesquisa, como também a produzirem projetos científicos de acordo com a área que satisfaça os seus interesses (RIBEIRO; SOUSA, 2014, p.6).

Em outras palavras, as atividades no núcleo visam tornar cada aluno um "aprendiz de pesquisador". Dessa forma, o ensino para alunos com AH/SD tem como base atividades desenvolvidas de forma específica, diferenciada e direcionada para sua área de domínio, possibilitando a ampliação dos conhecimentos e oferecendo condições para o desenvolvimento mais efetivo de seus estudos. Nesse contexto, o aprimoramento das práticas pedagógicas para alunos com Altas Habilidades/Superdotação deve receber uma atenção especial dentro das circunstâncias encontradas na realidade da Educação Especial no Brasil, de maneira que venha a suprir definitivamente as necessidades educacionais desses alunos para que seu rendimento seja o melhor possível e seu aproveitamento nos estudos, satisfatório.

\section{CONSIDERAÇÓES FINAIS}

Após realizarmos o levantamento e a análise das políticas educacionais existentes no Brasil e nos Estados Unidos relativas ao atendimento de alunos com Altas Habilidades/ Superdotação, identificamos que existem diferenças significativas, bem como semelhanças nas ações realizadas pelos dois países. Nos Estados Unidos as ações destinadas aos alunos com Altas Habilidades/Superdotação já existiam em 1900. Em contrapartida, no Brasil, é apresentada uma política educacional relativa ao assunto somente 60 anos depois. No Brasil, o Estado é indicado na legislação pertinente como responsável pelo atendimento a esse público, enquanto isso, nos Estados Unidos, esse atendimento é financiado pelo governo, mas desenvolvido parcialmente pela iniciativa privada. 
As leis americanas apresentam preocupação com a identificação desse alunado por meio de testes de identificação e com a definição do conceito. Porém, a legislação brasileira envolve tanto a definição dos conceitos, identificação desses sujeitos, bem como indica a ação estatal para o atendimento desse grupo, envolvendo a escola no processo e organizando núcleos de atendimento específicos. Isso significa que as políticas americanas não determinam como as ações devem ser implantadas, mas apenas indicam a necessidade de realização das mesmas. Já no Brasil, as políticas não só determinam que as açóes devam ser feitas, mas também indicam como elas devem ser realizadas.

Concluímos que o atendimento aos alunos com Altas Habilidades/Superdotação no Brasil ainda é um processo a ser desenvolvido, mas teve seu início por meio da implantação dos Núcleos de Atividades em Altas Habilidades/Superdotação. A compreensão de que esses alunos precisam de atendimentos específicos é uma das possibilidades de ampliação dos recursos e leis destinadas ao ensino desse grupo.

\section{REFERÊNCIAS}

ANDRÉS, A. Consultoria Legislativa da Área XV. Educação, Cultura e Desporto. Educação de alunos superdotados/altas habilidades - Legislação e normas nacionais e Legislação internacional. Brasília, DF, fev. 2010. Disponível em: <http://www2.camara.leg.br/documentos-e-pesquisa/publicacoes/estnottec/ tema11/2010_645.pdf>. Acesso em: 10 nov. 2014.

BAUM, S. Gifted but learning disabled: A puzzling paradox. ERIC Digest \#E479, 1990. Disponível em: <http://www.ericdigests.org/1994/paradox.htm>. Acesso em: 10 nov. 2014.

BRASIL. Ministério da Educação. Lei no 4.024, de 20 de dezembro de 1961. Lei de diretrizes e bases da educação nacional. Brasília, DF: MEC, 1961. Disponível em: <http://www.planalto.gov.br/ccivil_03/ leis/14024.htm>. Acesso em: 25 maio 2015.

BRASIL. Ministério da Educação. Lei no 5.692, de 11 de agosto de 1971. Lei de diretrizes e bases para o ensino de $1^{\circ}$ e $2^{\circ}$ graus. Brasília, DF: MEC, 1971. Disponível em: <http://www.planalto.gov.br/ ccivil_03/leis/15692.htm>. Acesso em: 25 maio 2015.

BRASIL. Constituição Federal de 1988. Constituição da República Federativa do Brasil de 1988.

Brasília, DF: Senado, 5 out. 1988. Disponível em: <http://www.planalto.gov.br/ccivil_03/constituicao/ ConstituicaoCompilado.htm>. Acesso em: 22 out. 2014.

BRASIL. Ministério da Educação e do Desporto. Secretaria de Educação à Distância. Política nacional de educação especial. Brasília, DF: MEC/SEESP, 1994.

BRASIL. Ministério da Educação. Lei no 9.394, de 20 de dezembro de 1996. Lei de Diretrizes e Bases da Educação Nacional. Brasília, DF: MEC, 1996. Disponível em: <http://www.planalto.gov.br/ ccivil_03/leis/19394.htm>. Acesso em: 20 out. 2014.

BRASIL. Ministério da Educação. Lei no 10.172, de 9 de janeiro de 2001. Plano Nacional de Educação. Brasília, DF: MEC, 9 jan. 2001. Disponível em: <http://www.planalto.gov.br/ccivil_03/leis/leis_2001/ 110172.htm>. Acesso em: 20 out. 2014.

BRASIL. Ministério da Educação. Angela M. R. Virgolim. Altas Habilidades/Superdotação: encorajando potenciais. Brasília, DF: MEC, SEESP, 2007. 70 p. Ilustrado. 
BRASIL. Ministério da Educação. Secretaria de Educação Especial. Política nacional de educação especial na perspectiva da educação inclusiva. Brasília, DF: MEC/SEESP, 2008.

BRASIL. Ministério da Educaçáo. Decreto no 7.611, de 17 de novembro de 2011. Dispóe sobre a educação especial, o atendimento educacional especializado e dá outras providências. Brasília, DF: MEC, 2011. Disponível em: <http://www.planalto.gov.br/ccivil_03/_Ato2011-2014/2011/Decreto/ D7611.htm\#art11>. Acesso em: 25 maio 2014.

BRASIL. Ministério da Educação. Decreto $n^{\circ}$ 7.690, de 2 de março de 2012. Aprova a Estrutura Regimental e o Quadro Demonstrativo dos Cargos em Comissão e das Funçóes Gratificadas do Ministério da Educação. Brasília, DF: MEC, 2012. Disponível em: <http://www.planalto.gov.br/ ccivil_03/_Ato2011-2014/2012/Decreto/D7690.htm\#art5>. Acesso em: 10 nov. 2014.

BRASIL. Ministério da Educação. Secretaria de Educação Continuada, Alfabetização, Diversidade e Inclusão. Diretoria de Políticas de Educação Especial. Nota Técnica No 04, de 23 de janeiro de 2014. Orientaçáo quanto a documentos comprobatórios de alunos com deficiência, transtornos globais do desenvolvimento e altas habilidades/superdotação no Censo Escolar. Brasília, DF: MEC / SECADI / DPEE, 23 jan. 2014.

BUENO, J.G.S. Educação especial brasileira: integração/segregação do aluno diferente. São Paulo: EDUC, 1993. (Série Hipótese).

GARCIA, R.M.C.; MICHELS, M.H. A política de educação especial no Brasil (1991-2011): uma análise da produção do GT15 - educação especial da ANPED. Rev. bras. educ. espec. [online], Marília, 2011, v.17, n.spe1, p.105-124. Disponível em: <http://dx.doi.org/10.1590/S141365382011000400009>. Acesso em: 25 maio 2015.

JANNUZZI, G. A luta pela educação do deficiente mental no Brasil. 2.ed. Campinas: Autores Associados, 1992.

MAIA, M.H. de. Consultoria Legislativa da Área XV. Educação, Cultura, Desporto, Ciência e Tecnologia. Ensino especial para superdotados. Brasília, DF, 2004. Disponível em: <http://www2. camara.leg.br/documentos-e-pesquisa/publicacoes/estnottec/tema11/pdf/2004_10717.pdf>. Acesso em: 10 nov. 2014.

MAZZOTTA, M.J.S. Educação especial no Brasil: história e políticas públicas. 4.ed. São Paulo: Cortez, 2003.

National Society for the Gifted \& Talented (NSGT). Giftedness Defined. United States of America, 2014. Disponível em: <http://www.nsgt.org/giftedness-defined/>. Acesso em: 10 nov. 2014.

PÉREZ, S.G.P.B.; FREITAS, S.N. Estado do conhecimento na área de altas habilidades/superdotação no Brasil: uma análise das últimas décadas. In: REUNIÃO DA ASSOCIAÇÃO NACIONAL DE PÓS-GRADUAÇÃO E PESQUISA EM EDUCAÇÃO (Anped), 32., Caxambu, 2009. Anais... Caxambu: Anped. Disponível em: <http://32reuniao.anped.org.br/arquivos/trabalhos/GT15-5514-Int.pdf>. Acesso em: 10 nov. 2014.

PÉREZ, S. P. B. Inclusão para superdotados. Ciência Hoje, São Paulo, v.41, n.245, p.8-11, 2007. Disponível em: < http://cienciahoje.uol.com.br/revista-ch/revista-ch-2008/245>. Acesso em: 10 nov. 2014. 
PRIETO, R. G. Políticas de inclusão escolar no Brasil: descrição e análise de sua implementação em municípios das diferentes regiôes. In: REUNIÃO DA ASSOCIAÇÃO NACIONAL DE PÓSGRADUAÇÃO E PESQUISA EM EDUCAÇÃO (Anped), 27., Caxambu, 2004. Anais... Caxambu: Anped. Disponível em: <http://27reuniao.anped.org.br/diversos/te_rosangela_gavioli_prieto.pdf>. Acesso em: 25 maio 2015.

RIBEIRO, F.F.; SOUSA, S.N. Alfabetização de alunos com altas habilidades/superdotação: considerações acerca das narrativas de mães/tutores sobre a trajetória de alunos "especiais". In: CONGRESSO INTERNACIONAL DE PESQUISA (AUTO) BIOGRÁFICA (CIPA), 6., 2014, Rio de Janeiro. Anais Eletrônicos... Campo Grande: Universidade Estadual de Mato Grosso do Sul, 2014. 1 CD.

TOLAN, S.S. Helping Your Highly Gifted Child. ERIC EC Digest\#E477, 1990. Disponível em: <http://www.ericdigests.org/1994/child.htm>. Acesso em: 10 nov. 2014.

TURNBULL, A.P. et. al. Exceptional lives: special education in today`s schools. 7 th ed. New Jersey: Pearson, 2013. chap. 16 p. 370-391.

UNITED STATES OF AMERICA. Gifted and Talented Children's Education Act of 1978. 1978. Disponível em: <www.gpo.gov/fdsys/pkg/STATUTE-92/pdf/STATUTE-92-Pg2143.pdf>. Acesso em: 10 nov. 2014.

VIRGOLIM, A.M.R. A inteligência em seus aspectos cognitivos e não cognitivos na pessoa com altas habilidades/superdotação: uma visão histórica. In: VIRGOLIM, A.M. R.; KONKIEWITZ, E.C. (Org.). Altas habilidades/superdotaçâo, inteligência e criatividade: uma visão multidisciplinar. Campinas: Papirus, 2014. p.23-64. cap. 1.

Recebido em: 16/07/2015

Reformulado em: 02/05/2016

Aprovado em: 03/05/2016 